\title{
Educação e produção de conhecimento em turismo e em lazer com base na dinâmica pedagógica de resolução de problemas
}

\author{
Education and knowledge production in tourism and leisure based on problem- \\ solving learning dynamic
}

\author{
Edegar Luis Tomazzoni (TOMAZZONI, E. L.)
}

\begin{abstract}
RESUMO - Em razão da diversidade de segmentos em turismo e lazer, a formação do profissional na área é, ao mesmo tempo, complexa e promissora. A aprendizagem baseada em resolução de problemas (ABP) diferencia-se significativamente da pedagogia tradicional, em que o professor, por meio de aulas expositivas, é o principal ator do processo de ensino. O objetivo deste artigo é analisar as contribuições da disciplina Resolução de Problemas II (RP II) para o ensino e para a produção de conhecimento em turismo e lazer. A disciplina integra a grade curricular do Curso de Lazer e Turismo, da Escola de Artes, Ciências e Humanidades (EACH), da Universidade de São Paulo (USP). No método do artigo, descreve-se a dinâmica pedagógica e, como exemplos, destacam-se dez estudos produzidos, nos anos de 2012 e 2013, pelos grupos de alunos. A experiência mostra que o intercâmbio de ideias, por meio de discussões, as pesquisas de campo e o autoaprendizado instigam os alunos dos primeiros semestres do curso à produção de conhecimentos e ao desenvolvimento de habilidades para intervenções na realidade e para atuação no mercado de trabalho.
\end{abstract}

Palavras-chave: Turismo e Lazer; Educação; Problemas; Conhecimento; Autoaprendizagem.

ABSTRACT - Since there is a diversity of segments in tourism and leisure, professional formation in area is at the same time, complex and promising. The problem based learning (PBL) method differs significantly from the traditional pedagogy, where the teacher, through lectures, is the main responsible for the teaching process. The aim of this paper is to analyze the contributions of the discipline of Solving Problem II (SP II) for teaching and for the production of knowledge in tourism and leisure. The subject is part of the curriculum of the Leisure and Tourism Course, at the School of Arts, Sciences and Humanities, from São Paulo University (USP). The methodology describes the pedagogical dynamics and, as examples, it is shown ten case studies produced in 2012 and 2013 by students groups. The experience shows that the exchange of ideas through discussions, field research and self-learning instigates students in the first semesters of the course to produce knowledge and develop skills, make interventions in reality and work in this area.

Key words: Tourism and Leisure; Education; Problems; Knowledge; Self-Learning.

\footnotetext{
* Formação: Graduação em Engenharia Química (PUCRS), Especialização em Administração (UFRGS). Mestrado em Turismo (UCS). Doutorado em Ciências da Comunicação com Ênfase em Turismo pela Escola de Ciências e Comunicações (ECA) da Universidade de São Paulo (USP). Atividade profissional: Docente do Mestrado em Turismo, do Mestrado em Mudança Social e Participação Política e do Curso de Graduação em Lazer e Turismo, na Escola de Artes Ciências e Humanidades (EACH), da Universidade de São Paulo (USP). Endereço físico para correspondência: Bloco I 1, sala 303H, rua Arlindo Bettio, 1000, bairro Ermelino Matarazzo. CEP 03828-000 - São Paulo (Brasil). E-mail: eltomazzoni@ usp.br
} 


\section{INTRODUÇÃO}

Para a empregabilidade em turismo, implementam-se métodos de qualificação, e definem-se competências profissionais de acordo com o mercado de trabalho. Na educação em turismo, as dinâmicas pedagógicas contextualizam-se nas políticas de formação profissional das demais atividades, resguardadas suas características e peculiaridades socioculturais. $\mathrm{O}$ ensino em turismo, como atividade econômica, enfoca a atuação profissional na sociedade de consumo de lazer como produto.

A atuação acadêmica, no campo do turismo, é questionada quanto à relação entre a oferta de propostas pedagógicas pelas universidades e a demanda de profissionais competentes pelas organizações. Os coordenadores, gestores acadêmicos, professores e alunos das universidades e faculdades de turismo e de áreas afins (hotelaria, gastronomia, hospitalidade) do Brasil discutem a qualidade das propostas pedagógicas e a eficácia dos programas de formação.

Enfatiza-se a necessidade de articulação entre teoria e realidade, para formar profissionais com capacidade técnica e, também, com capacidade de reflexão. Entre os desafios para ampliar os espaços para atuação profissional dos egressos dos cursos superiores de turismo, estaria aumentar o conhecimento das competências profissionais do turismólogo pelos atores organizacionais do setor.

Como exemplos de questionamentos sobre a formação acadêmica, têm-se: São oferecidas atividades práticas extraclasses? A instituição preocupa-se em preparar o aluno também para a pesquisa? Os alunos são motivados ao empreendedorismo, por meio de disciplinas especiais do curso? Quais são os conteúdos e as dinâmicas pedagógicas eficazes e produtivos?

O presidente do Conselho Nacional de Pesquisa (CNPq), Glacius Oliva, declarou em entrevista às páginas amarelas da revista Veja, edição de 27 de março de 2013, que os métodos de ensino nas universidades brasileiras estão ultrapassados. Para ele, mesmo na USP, as aulas têm cargas horárias insensatas, são maçantes e seguem o antigo modelo expositivo, em que o professor é a autoridade monopolizadora e único detentor do conhecimento. Essa visão do presidente do CNPq representa as causas da frustração e do desencantamento de muitos alunos com os métodos de ensino no Brasil. 
Nesse contexto de questionamentos e discussões, o objetivo deste artigo é analisar as contribuições da disciplina Resolução de Problemas II para o ensino e para a produção de conhecimento em turismo e lazer. A disciplina integra a grade curricular do curso de Lazer e Turismo, da Escola de Artes, Ciências e Humanidades (EACH), da Universidade de São Paulo (USP). O curso foi criado em 2005 e oferece 120 vagas por ano. O número médio de candidatos por vaga é entre quatro e cinco, e o ingresso é por meio de vestibular. Desde sua criação, formaram-se cinco turmas (350 alunos).

Além desta introdução, este artigo estrutura-se em referencial teórico, cujas seções são: educação e formação em turismo; aprendizagem baseada em problema; método, em que se descrevem os procedimentos da dinâmica pedagógica, que constituem o próprio método da produção deste artigo; sínteses de trabalhos realizados na disciplina de Resolução de Problemas II; reflexões sobre a experiência; e conclusões, em que se mostram a eficácia e as contribuições da pedagogia baseada em problemas na educação em turismo e lazer.

\section{EDUCAÇÃO E FORMAÇÃO EM TURISMO}

A formação do profissional em turismo é, ao mesmo tempo, complexa e promissora, em razão de reunir segmentos que vão desde hotelaria, transportes, agenciamento de viagens, organização de eventos, até criação de produtos, serviços e atrativos. No campo da epistemologia, é recorrente o questionamento do conceito de turismo, em relação à ideia do senso comum, que identifica a prática de viajar e de desfrutar de lazer. Esse questionamento não torna a ideia menos relevante, pois o objetivo é esclarecer o sentido do estudo e da pesquisa em turismo como campo científico. (BENI, 2002; MOESCH, 2002; MOLINA, 2003; JAFARI, 2005; PANOSSO NETTO, 2011).

Os próprios profissionais do ensino não têm clareza do real sentido de educação. Falta consciência de que ensinar é sinônimo de educar. Os métodos eficazes de ensino e de avaliação não são priorizados. Transmitem-se informações com intuito de que o aluno se habilite a atuar no desempenho econômico do turismo e do lazer. (STERGIOU; AIREY; RILEY, 2008). As expectativas e necessidades dos alunos transcendem a 
qualificação profissional, e os métodos pedagógicos devem proporcionar reflexões sobre a realidade e vivências para a ação transformadora virtuosa, com base em valores morais, comportamentais e culturais.

A eficácia da educação depende da mentalidade e das visões articuladoras e sistêmicas dos docentes, dos gestores acadêmicos e dos atores sociais do turismo. $\mathrm{O}$ aluno deve atuar ativamente na dinamização e na interatividade dos conteúdos teóricos e na sua aplicação à análise da realidade para produção de conhecimentos. (MORIN, 2002; SANTOS, 2007; TRENTIN e SILVA, 2010).

Sampaio e Paixão (2012, p. 438) argumentam que "as universidade regionais ou que estejam instaladas em regiões com desigualdades históricas, como é habitual no contexto brasileiro, acolhem alunos e alunas academicamente vulneráveis". Para os autores (2012, p. 438):

[...] o processo de ensino-aprendizagem convencional produz efeitos nocivos na sala de aula e nos campi universitários. A apatia dos estudantes, a mediocridade implantada como norma, a ausência de reflexão crítica, a exacerbação monodisciplinar na transmissão do conhecimento e os modelos autoritários de ensino, associados à absoluta desvinculação com o meio regional, são parte da sintomatologia de uma situação universitária que exige melhoras substanciais.

Entre as funções das instituições de ensino e pesquisa, está o estudo sobre os problemas que impedem, ou dificultam tanto o desenvolvimento socioeconômico quanto o desenvolvimento do turismo. Além disso, questionam-se as aplicações dos estudos nas transformações positivas da realidade. A relação entre teoria e prática na formação profissional é questão recorrente nos meios acadêmico, social e das organizações de mercado.

A formação deve contemplar os conhecimentos estruturantes, comuns aos serviços ou segmentos essenciais do turismo (hotelaria, gastronomia, transportes, lazer), bem como a interação com outras áreas do conhecimento, com base na visão sistêmica e na interdisciplinaridade. Os projetos pedagógicos devem ser adequados às diretrizes jurídico-institucionais, que estabelecem as competências fundamentais do profissional a ser formado pela academia. A gênese dos projetos pedagógicos fundamenta-se no tempo necessário para a formação, bem como no enfoque da relação entre a realidade local e a realidade global. 
Enquanto os docentes devem ter perfil profissional adequado às disciplinas que ministram e atuar de forma eclética em pesquisa, com base na visão da realidade sociológica e mercadológica, os alunos devem ser motivados ao empreendedorismo e à cidadania, de acordo com paradigmas éticos. Para Ferreira (2004, p. 196):

\begin{abstract}
Especificamente para a formação superior em turismo, considerando todas as questões anteriormente expostas, fica evidente a necessidade de o educador atuar como: a) orientador dos alunos em atividades de pesquisa, seja em campo ou na revisão bibliográfica; b) incentivador da atitude de compartilhar informações com os colegas através de apresentações; c) moderador nos acordos para desenvolver os relacionamentos interpessoais através do trabalho em equipes; d) apresentador de situações e mediador no estudo de casos baseados em experiências de sucesso e também nos exemplos problemáticos; e) mediador da auto avaliação e análise crítica quanto aos erros e acertos das experiências individual e coletivamente vivenciadas; f) promotor do contato direto dos acadêmicos com a comunidade dos núcleos receptores de turismo e com os próprios turistas.
\end{abstract}

É fundamental manter constante e dinâmico intercâmbio com os diversos segmentos da sociedade e do mercado. A comunicação e o monitoramento de necessidades de mudanças são estratégias de conhecimento das competências dos alunos pelos empresários, pelos profissionais do mercado e pelos gestores públicos.

A qualificação e a capacitação dos docentes são fundamentais e devem enfatizar suas áreas específicas de especialidades, por meio das quais proporcionam conhecimento aos alunos. Em razão da multidisciplinaridade e da interdisciplinaridade, o professor não pode dominar todas as diferentes áreas do ensino em turismo. Os gestores das instituições de ensino têm a responsabilidade de valorizar e de motivar seus docentes.

Silveira, Medaglia e Gândara (2012, p. 17) argumentam que "é interessante que na área de turismo, tenha-se perdido a imagem da academia como orientadora do mercado e divulgadora de novas tendências (se é que tal status já existiu no Brasil)". Para os autores:

A manutenção do ensino superior à luz da evolução da legislação implicou aprofundamento dos estudos por meio da qualificação de professores em mestrados e doutorados. Em decorrência disso, ao contrário do que se esperava, que a academia se adaptasse ao mercado, fornecendo profissionais bem "treinados", houve uma busca por aprofundamento teórico mais que prático, e uma área profissional que despontou nos anos 1970 e gerou uma expectativa de formação superior, não chegou a consolidar-se como profissão regulamentada, mas gerou tamanho interesse no meio acadêmico que é 
possível que a consolidação da área de estudo e da epistemologia do turismo esteja mais próxima de consolidar-se do que a profissão de turismólogo no Brasil.

As propostas pedagógicas das dezenas de cursos superiores de turismo apresentam as habilidades ou competências do profissional a ser formado e os atributos do perfil do egresso. Tem-se, portanto, que há mais semelhanças do que diferenças entre as propostas didáticas, cujos conteúdos são sistematizados em linhas ou em conjuntos de disciplinas. As abordagens inerentes à educação em turismo são: serviços, qualidade, hospitalidade, empreendedorismo, sustentabilidade, desenvolvimento socioeconômico, entre outras.

Alguns autores enfatizam limitações e questionam as ausências de conteúdos multiculturais, bem como de temas da comunicação interpessoal e da ética nas relações sociais, políticas e econômicas para o fortalecimento do espírito de cooperação e de socialização de benefícios da atividade turística. Com base na análise da formação e da atuação do turismólogo no âmbito das agências de turismo, Bridi (2010) argumenta que o conceito de competência operacional fundamenta-se na articulação entre saberes, fazeres e atitudes.

É consenso que o aluno deve ser valorizado como ser humano, tanto em sua dimensão individual quanto em seu papel de participante da coletividade, cujas ações implicam atitudes éticas na articulação entre teoria e prática. Essa valorização é fundamental para que o aluno aprenda a resolver tanto os próprios problemas quanto os problemas de seu contexto social.

Baptista (2008) aborda os princípios do processo educacional e destaca a necessidade de se observar os desdobramentos da reflexão sobre ética e vida moral, teoria e prática, fundamentação versus aplicação, integrando o setor normativo e os padrões de conduta com a ação. Cita a importância de valorização das pessoas na resolução dos próprios problemas, exaltando o papel dos principais atores envolvidos nos processos, isto é, os alunos.

O aspecto relacional entre os indivíduos também é destacado por Santos, Oliveira e Marinho (2009). O aprimoramento moral deve ser visto tanto como processo social quanto pessoal; deve ser pautado em princípios da racionalidade comunicativa, cooperativa e interdisciplinar, respeitando as particularidades das situações estabelecidas e dos contextos social e histórico dos grupos envolvidos. 
No mesmo sentido do pensamento de Baptista (2008), Bonfim (2010, p. 117) destaca a necessidade de educar para a transformação social "a formação do cidadão político, que usa a palavra como forma de transformar o mundo". Para Bonfim (2010, p. 116):

[...] o distanciamento da realidade, representada por visões alienadas sobre o que acontece ao nosso redor, pode ser superado no âmbito escolar, por meio de uma pedagogia que pretenda o desenvolvimento da autonomia dos alunos e que vise a envolvimento efetivo deles nos trabalhos, o que implica prazer.

Sogayar e Rejowski (2011) concordam com os benefícios econômicos do turismo e, com base nas discussões sobre a necessidade de valorização das dimensões cultural, social e ambiental da atividade pela comunidade acadêmica, propõem que o ensino na área transcenda essa visão e se fundamente em três fatores: 1) internacionalização (globalização); 2) sustentabilidade; e 3) ética. As justificativas são respectivamente: as relações de poder econômico e o intercâmbio cultural; os impactos ambientais e as mudanças climáticas; e a orientação das condutas individuais. As autoras destacam também a hospitalidade como verdadeiro sentido de humanização do turismo.

\section{A APRENDIZAGEM BASEADA EM PROBLEMAS (ABP)}

A atuação de professores qualificados e em condições ambientais adequadas é essencial para a qualidade e o sucesso dos cursos. Quanto maior a participação de todos os atores (professores e alunos) nas propostas pedagógicas e curriculares, mais favoráveis serão as condições de eficácia da aprendizagem e de qualidade da educação. Um dos desafios é o monitoramento da satisfação dos alunos, dos egressos e dos responsáveis pelo mercado para identificar necessidades e atender expectativas.

Com base na visão dos sete saberes da educação do futuro, de Morin (2004), e na pedagogia libertadora de Freire (1997), é importante reconhecer a atuação dos atores da sociedade e do mercado, tanto no sentido de empreendedorismo quanto no sentido de produção de conhecimento com base nos saberes tácitos, espontâneos e vivenciais da realidade. 
A aprendizagem baseada em resolução de problemas diferencia-se significativamente da pedagogia tradicional, em que o professor, por meio de aulas expositivas, é o principal ator do processo de ensino e aprendizagem. Entre os diferenciais da proposta, destaca-se a liberdade de escolha dos meios e dos recursos de estudo pelos alunos, que são instigados pelo professor a identificar as fontes da fundamentação teórica. Essa estratégia (bem como todo o processo da disciplina) estimula os alunos à autoaprendizagem.

As características inovadoras do método são a proatividade do aluno e a postura interativa do professor, que assume papel de tutor, e cuja presença e participação mantêm-se essenciais. Na condição de tutor, o professor explica os procedimentos metodológicos, organiza e articula os grupos, acompanha e monitora os trabalhos, orienta e informa sobre conteúdos e referenciais teóricos, questiona o desempenho e os resultados e avalia os projetos e relatórios de pesquisa produzidos pelos alunos.

Historicamente, entre as razões do surgimento dessa dinâmica pedagógica, estão o avanço da tecnologia da comunicação e da informação, a velocidade da produção de conhecimentos e das mudanças da sociedade. A internet e a expansão dos veículos de imprensa democratizaram a facilitaram o acesso à informação e à educação. Nesse contexto, questionou-se o método tradicional de ensino-aprendizagem, cuja dinâmica é a exposição de conteúdos exclusivamente pelo professor, a memorização pelo aluno e a aferição da assimilação por meio de provas.

A metodologia do novo modelo, que se denominou Problem Based Learning (PBL), ou Aprendizagem Baseada em Problemas (ABP), surgiu no final de década de 1960, na Universidade de Maastricht e foi também aplicado na Universidade de McMaster (Canadá). Entre outros referenciais, a Aprendizagem Baseada em Problemas fundamenta-se na filosofia da educação, do filósofo americano John Dewey (19521959), cuja proposta é o desenvolvimento da visão crítica do aluno. (DEWEY, 1961, 1979a, 1979b).

A atribuição de excessiva responsabilidade ao professor, como protagonista central da educação, implicou mudanças do paradigma pedagógico, por meio de atividades interativas. No método ABP, formam-se grupos em que os alunos buscam a solução de problemas por meio de estudos de casos. Nesse processo, o aluno é motivado à produção de conhecimentos pela revisão e aplicação de conceitos à análise da 
realidade e à elaboração de novos conceitos. O educador é menos pressionado pelas exigências de domínio de conteúdos, pelas avaliações de desempenho, pelos gestores e pelos alunos, reduzindo-se riscos de desgastes psicológicos e profissionais de não atender às expectativas de atualização e de monopolização de conhecimentos.

Além da reflexão sobre questões de seu interesse e de interesse coletivo e da criatividade nas soluções de problemas reais, os alunos são estimulados a trabalhar em equipe, a respeitar diferentes visões e a implementar métodos científicos fundamentados nos valores morais e humanísticos da sociedade. A razão da motivação e do comprometimento da equipe é o desafio da solução de problemas da realidade vivencial dos alunos. Nesse sentido, os docentes tutores da disciplina, que faz parte da estrutura curricular de cursos superiores, tanto das ciências sociais e humanas quanto das ciências exatas, podem sugerir diversas temáticas orientadoras, a fim de facilitar a definição e a contextualização do problema pelos grupos de alunos. O mais coerente é que os próprios alunos definam as temáticas, de acordo com o contexto epistemológico de seus cursos.

Em cenário de globalização e de intensificação da competição, aumenta a necessidade de cooperação para o desenvolvimento de competências por métodos descentralizados, em que predominem a participação e o comprometimento individual com a equipe e com a coletividade. Comunicação, intercâmbio de ideias, interatividade e iniciativa são habilidades exercitadas na formação de competências para lidar com incertezas, por meio de visões inovadoras que articulem a teoria com a realidade. Ao mesmo tempo em que é incentivado ao autoaprendizado, o aluno aprende a estabelecer relacionamentos profissionais e a tomar decisões com base no espírito democrático e no consenso.

Além da dimensão analítica das discussões pedagógicas, os grupos de alunos devem planejar e executar tarefas, cumprindo prazos para produzir o relatório de atividades, cujo formato é de trabalho científico. O problema é traduzido em questão de pesquisa para a qual deve ser elaborada justificativa com argumentação da relevância do estudo. Além desses elementos, a estrutura do trabalho constitui-se em: objetivos (geral e específicos), fundamentação teórica, método de estudo do caso (instrumentos de investigação de campo e sujeitos abordados), descrição e análise dos resultados e 
conclusões. (DENCKER, 2007). Essa estrutura não é determinante, mas é a mais adequada e usual para a organização das atividades da equipe.

\section{MÉTODO}

Descrevem-se neste tópico os procedimentos da dinâmica pedagógica, que constituem o próprio método da produção deste artigo. Os trabalhos, cujas sínteses são apresentadas neste estudo, foram produzidos por grupos de alunos da disciplina de Resolução de Problemas II, do Curso de Lazer e Turismo, da Escola de Artes, Ciências e Humanidades (EACH), da Universidade de São Paulo (USP). O Curso tem duração de quatro anos (oito semestres), oferendo 65 disciplinas, que somam 3.060 horas de atividades. Além deste, a EACH oferece mais nove cursos de graduação. A disciplina de Resolução de Problemas (RP) faz parte do currículo de todos os cursos. No primeiro semestre, na disciplina de Resolução de Problemas I (RP I), os temas são abrangentes e multidisciplinares. A disciplina de Resolução de Problemas II (RP II) integra a grade curricular do segundo semestre e focaliza temas específicos do curso.

Para a produção deste artigo, foram destacados dez trabalhos da disciplina de Resolução de Problemas II, produzidos em 2012 e 2013. A primeira etapa da disciplina foi explanação da dinâmica pedagógica e do método de elaboração de projetos de pesquisa. A dinâmica expositiva, em que dois professores exerceram o papel tradicional de transmissores de informações aconteceu apenas no primeiro encontro. Do segundo encontro em diante, as turmas (com cerca de 60 alunos) foram divididas entre os dois professores e organizadas em quatro grupos de sete a oito alunos.

Além dos professores, houve a atuação de dois monitores, alunos de cursos de pós-graduação stricto sensu (mestrado). As discussões dos grupos iniciaram com a definição das temáticas e dos problemas de pesquisa. Para a fundamentação teórica do projeto, os alunos fizeram revisões bibliográficas e, uma vez definidos os objetivos do trabalho, estabelecem-se os procedimentos de pesquisa de campo.

O tutor, de forma interativa, atuou na verificação da clareza dos objetivos da pesquisa, na orientação dos alunos, na elaboração de todas as etapas do projeto. Questionou a eficácia e a viabilidade dos procedimentos metodológicos, bem como a credibilidade das fontes de pesquisa. Incentivou as discussões e a valorização da 
diversidade de visões e de opiniões, com base no rigor científico e no pluralismo de ideias e de pontos de vistas. Manteve constante diálogo e intercâmbio com os alunos e também com os colegas tutores.

As atividades desenvolveram-se ao longo de dezoito encontros de quatro horasaula, totalizando 54 horas em sala de aula. Além desse tempo, os grupos atuaram extraclasses, realizando visitas e encontros e mantendo contatos virtuais. Os projetos dos relatórios (trabalhos de pesquisa) foram apresentados por todos os grupos aos cerca de 60 alunos da disciplina e foram avaliados presencialmente e imediatamente após as apresentações pelos tutores (os dois professores e os dois monitores).

Ao final do semestre, os alunos apresentaram, à turma de cerca de 60 alunos, os trabalhos completos, que foram avaliados presencialmente pelos tutores e monitores. Além das apresentações, os grupos entregaram versão do trabalho em texto impresso, com limite de 20 páginas e adequado às normas da ABNT. O conceito, ou nota, final dos alunos foi definido com base nas avaliações dos trabalhos pelos professores e monitores e pelas autoavaliações dos alunos que atribuíram notas a si e aos colegas de grupo.

\section{SÍNTESES DE TRABALHOS PRODUZIDOS}

Apresentam-se as sínteses de dez trabalhos produzidos pelos grupos de alunos da disciplina de Resolução de Problemas II. Esses trabalhos representam dezenas de estudos produzidos pelos grupos de alunos da disciplina, desde a criação do Curso de Lazer e Turismo, em 2005, na Escola de Artes, Ciências e Humanidades (EACH), da Universidade de São Paulo (USP).

- Acessibilidade dos cadeirantes ao Parque da Juventude e ao Parque Ecológico Tietê (cidade de São Paulo)

Vivenciando na prática, por meio da técnica de simulação (observação participante), os problemas enfrentados pelos cadeirantes em sua locomoção de casa até equipamentos de lazer, o trabalho analisou obstáculos e sugeriu melhorias da 
acessibilidade no itinerário. O estudo concluiu que o trajeto da estação Engenheiro Goulart ao Parque Ecológico do Tietê, na cidade de São Paulo, era árduo para o cadeirante se locomover sozinho, em razão das barreiras urbanas. O Parque Ecológico do Tietê não cumpria os padrões exigidos para a acessibilidade segundo as normas da Associação Brasileira de Normas Técnicas (ABNT). Foram constatados diversos pontos de inadequação, devidos às barreiras arquitetônicas, causadores de dificuldades aos portadores de deficiência física, no caso os cadeirantes, em sua locomoção.

- Os serviços da rede hoteleira e as expectativas do público LGBT a lazer na cidade de São Paulo

O estudo analisou a qualidade do atendimento de hotéis da cidade de São Paulo aos segmentos de públicos lésbicas, gays, bissexuais, travestis, transgêneros e simpatizantes (LGBT), com base em aplicação de questionários e em realização de entrevistas com gestores e funcionários de 15 grandes meios de hospedagem. A maioria dos respondentes não ofereceu ou recebeu qualificação e não prestava serviços especiais a esses segmentos de público, pois, para eles, os hóspedes preferem e não devem ser tratados com distinção. Metade dos respondentes afirmou disponibilizar informações de programações de lazer a esse segmento de clientes, por meio de revistas, folders e da internet. Todos os respondentes afirmaram manter funcionários homossexuais em suas equipes. Em síntese, verificou-se que os 15 hotéis da cidade de São Paulo ainda apresentavam limitações no atendimento ao público LGBT.

- As mudanças do lazer infantil com base em estudos de grupos de crianças e idosos da região central da cidade de São Paulo

A urbanização e a evolução da tecnologia constituem a realidade das crianças contemporâneas. Equipamentos como computadores, videogames, televisão, telefones celulares são inerentes às suas rotinas. Espaços onde haveria possibilidade de brincar têm-se reduzido significativamente nas grandes áreas metropolitanas. Observar, por meio da comparação de grupos focais, da região central da cidade de São Paulo, as mudanças no lazer infantil das crianças nos dias atuais, comparativamente ao lazer 
infantil na década de 1950. A pesquisa de campo foi por aplicação de questionários a amostras intencionais de sessenta indivíduos, trinta idosos entre 60 e 70 anos e trinta crianças, com idades entre sete e dez anos, de ambos os sexos e de classe média. As ações governamentais priorizam diversas áreas como saúde, emprego e educação, desconsiderando o potencial educacional do lazer para a sociedade. Brincadeiras tradicionais como pega-pega, esconde-esconde, amarelinha, entre outras, são cada vez menos praticadas e estão se perdendo. As tecnologias da informação e da comunicação restringem a convivência e a socialização infantil.

- Análise comparativa dos parques públicos paulistanos Chico Mendes, Independência e Raul Seixas sob a ótica dos frequentadores

Com objetivo de analisar comparativamente a qualidade dos parques paulistanos, Raul Seixas, da Independência e Chico Mendes, a pesquisa consistiu em aplicação de questionários a 50 frequentadores de cada equipamento. Os parques Chico Mendes e Raul Seixas foram dois dos piores classificados, em São Paulo, no ranking do Sindicato Nacional das Empresas de Arquitetura e Engenharia Consultiva (SINAENCO). Foram avaliados, porém, como bons pelos seus frequentadores, tanto em relação ao acesso, à segurança, ao atendimento dos funcionários e, praticamente, todos os itens de infraestrutura. O único item em que houve classificações regulares, ruins e péssimas foi a manutenção. Contrariamente às opiniões dos frequentadores, o estudo do SINAENCO destaca as más condições dos sanitários e dos bebedouros no Parque Chico Mendes. Para eles, o pior ponto é o consumo de drogas. O ponto positivo mais destacado no parque Chico Mendes foi a vegetação. A grande reclamação dos usuários no Parque Independência foi a manutenção do prédio do Museu Paulista. O SINAENCO como excelentes os bebedouros e sanitários, porém, muitos frequentadores os classificaram como péssimos, ruins e regulares.

- Atrativos turísticos e culturais em São Paulo durante a Copa do Mundo de 2014

Com base na questão de pesquisa "A cidade de São Paulo oferecerá programação turística cultural específica para a Copa do Mundo de 2014?”, o objetivo 
do trabalho foi analisar os atrativos culturais e as programações turísticas da cidade de São Paulo para a Copa do Mundo de 2014. O referencial teórico abordou a oferta de atrativos culturais, os fatores que os constituem e o histórico do megaevento Copa do Mundo. O método consistiu em entrevistas com gestores de órgãos públicos e privados, além de especialistas na área. Com base na análise das respostas, verificou-se que os gestores tinham visões diferentes sobre a Copa do Mundo de 2014. A maioria apenas reflete sobre o tema, sem planejamento estratégico eficaz e produtivo, tanto para os turistas quanto para a cidade que sediaria o evento.

- A Copa de 2014 e a mobilidade urbana: a ciclovia Tatuapé-Itaquera, na Zona Leste, cidade de São Paulo, na perspectiva da população local

Com aplicação de questionários, a maior parte dos 213 respondentes mostrou-se interessada em ir aos jogos da Copa no Estádio do Itaquerão, porém, mais da metade afirmou que não utilizaria a bicicleta para ir aos jogos durante a copa, ou para ir a jogos depois da copa. Alguns sequer sabiam que havia ciclovia direta para o Estádio Itaquerão. A maioria não utilizava a bicicleta para trabalhar, em razão da distância, porém, mais de $80 \%$ dos entrevistados utilizavam a ciclovia para o lazer, mesmo que grande parte das pessoas não tenha bicicleta ou nunca tenha tentado alugar uma. A pesquisa mostrou poucos interessados no uso das ciclovias e das bicicletas, tanto para ir ao trabalho quanto para assistir aos jogos da Copa em 2014. A educação para a utilização da bicicleta ainda é muito limitada, e os investimentos para a construção de ciclovias é quase nulo. É importante que os utilitários de automóveis respeitem os ciclistas, pois as ciclovias seriam benéficas para o trânsito, reduzindo os congestionamentos e a poluição da Zona Leste, a região mais populosa da cidade.

- Gastronomia de experiência: aspectos inovadores de cinco restaurantes da cidade de São Paulo

O objetivo do estudo foi analisar a relação entre gastronomia e lazer com base em diferenciais em estruturas, temáticas e formas de atendimento de cinco restaurantes paulistanos. Os estabelecimentos focalizam diferentes propostas: o Dinner in the Sky 
enfatiza o ambiente; o Hooters, além do ambiente, destaca-se pelo atendimento personalizado; o foco do Lab Club é a gastronomia molecular; o Ateliê no Escuro diferencia-se pela experiência gastronômica sensorial; e o Tantra diferencia-se por ambiente, espetáculos e gastronomia exótica. Essa modalidade gastronômica está em expansão no mercado brasileiro. Todos os gestores entrevistados confirmaram a lucratividade de seus empreendimentos, e o aumento da procura por essas experiências. Muitos clientes deixaram de procurar estabelecimentos apenas para comer, mas como experiência gastronômica lúdica e prazerosa.

- As práticas noturnas de lazer e a convivência entre as culturas juvenis na região paulistana da Baixa Rua Augusta

Com objetivo de analisar a prática de lazer noturno, os resultados da aplicação de 120 questionários a frequentadores mostraram que 60\% classificaram como bom, e 17\% com excelente o espaço da Baixa Rua Augusta. A variedade de atrativos atrai públicos diferentes, e a convivência entre pessoas de padrões culturais e comportamentais diversos é enriquecedora. A Baixa Rua Augusta tem muitos problemas de infraestrutura, iluminação, coleta de lixo, trânsito, acessibilidade das calçadas, segurança, entre outros. Falta atuação do setor público, planejamento urbano e educação. Esses problemas, porém, não impedem os frequentadores de desfrutar daquele espaço de lazer noturno, que se destaca também como um dos atrativos culturais e turísticos mais importantes da cidade de São Paulo.

- Análise da atuação de 30 agências de viagens brasileiras no segmento de turismo de pessoas com deficiências e mobilidade reduzida

O objetivo do trabalho foi analisar a adequação da oferta de pacotes por agências de viagens brasileiras para pessoas com deficiências auditivas, visuais, físicas e com mobilidade reduzida. Com base nos questionários aplicados a gestores de 30 agências de viagens, verificou-se que o mercado turístico ainda é despreparado para o tratamento do público portador de alguma deficiência física. São raros os locais, os serviços e o atendimento adaptados a esse segmento. Esse problema não é de responsabilidade 
apenas de um setor, no caso do estudo o turismo e o segmento de agências, mas abrangente, uma vez que a exclusão de pessoas com deficiência é inerente à vida em sociedade. Tanto o governo quanto o setor privado devem promover o bem estar, realizando não somente políticas de inclusão, mas principalmente, conscientizando a população para que o portador de deficiência tenha condições de vida dignas e normais.

- O consumo de produtos, serviços e atividades de lazer e a procedência dos frequentadores do evento Z Festival na cidade de São Paulo

O objetivo do estudo foi identificar o consumo e a avaliação da qualidade de produtos, serviços e atrativos de lazer pelos frequentadores do evento $Z$ Festival realizado na cidade de São Paulo. De acordo com questionários aplicados a 530 frequentadores do evento, $81 \%$ (maioria dos quais procedentes da grande São Paulo e do interior do estado) avaliaram o lazer da cidade de São Paulo como bom ou excelente, em razão da variedade de espaços e equipamentos. $64 \%$ viajaram à cidade somente para o evento, permanecendo um dia, o que não lhes possibilitou outras atividades de lazer. Muitos optaram por shoppings pela acessibilidade e por compras e alimentação. Por terem permanecido mais de um dia na cidade, $12 \%$ visitaram pontos turísticos. Aqueles que consideraram as atividades de lazer da cidade regulares apontaram a violência, a falta de divulgação, de qualificação profissional e de organização como os maiores problemas da cidade.

\section{ANÁLISE DA EXPERIÊNCIA PEDAGÓGICA}

Aspectos enfatizados pelas teorias da educação, como objetividade, intercâmbio, espírito de cooperação, parceria e participação, implementam-se na prática pedagógica da disciplina de Resolução de Problemas II (RP II), tornando a aprendizagem dinâmica e atualizada. Comprova-se que, desde os primeiros semestres do curso, os alunos podem ser empreendedores do conhecimento e participantes da produção de conteúdos científicos em turismo e lazer. Exemplos dessa possibilidade são os resumos dos trabalhos produzidos pelos grupos de alunos da disciplina, e novas propostas 
pedagógicas podem ser implementadas. Na maioria dos procedimentos metodológicos dos trabalhos, as pesquisas de campo, além de observação direta, realizaram-se por meio de entrevistas com gestores e de aplicações de questionários a amostras representativas dos universos de sujeitos responsáveis pelos casos de estudos.

A coordenação das atividades didáticas da disciplina de RP II em Turismo e Lazer proporciona espaço aos alunos e os motiva à responsabilidade e à reflexão, bem como à socialização dos estudos. Ainda que as pesquisas sejam delimitadas às realidades da cidade de São Paulo, os resultados dos trabalhos de grupos têm aplicabilidade universal. Os alunos têm interesse em reflexões e em análises de soluções de problemas e esperam que a academia lhes proporcione espaços e visões teóricas que se apliquem aos contextos sociais que eles vivenciam ou com os quais se identificam.

Entre os problemas de interesse dos alunos, estão, por exemplo, a deficiência da acessibilidade e da mobilidade, em vários espaços urbanos, e os estudos da disciplina de RP II proporcionam visões de melhoria da qualidade dos atrativos e serviços de parques e de áreas de lazer. Os alunos também identificam necessidades de melhoria do atendimento dos serviços de hospedagem e das agências de viagens para os diversos segmentos de clientes, especialmente, os deficientes, os idosos e os homossexuais. Destacam os exemplos de inovação e de competitividade de diversos estabelecimentos de gastronomia. Entre as múltiplas possibilidades de estudos e pesquisas, questionaramse os atrativos e legados da Copa do Mundo 2014 e os retornos dos festivais musicais, contemplando-se os eventos como campo relevante em turismo e em lazer. A premissa de que a cidade somente é hospitaleira para os turistas se for agradável para seus habitantes está implícita nos exemplos de estudos sobre as modalidades e dimensões temporais e espaciais de lazer.

A dinâmica da disciplina confirma a eficácia do método pedagógico baseado em problemas (ABP), pois o aluno é instigado a comprometer-se com o autoaprendizado em interlocução produtiva com o professor. O aluno torna-se, portanto, proativo, e o professor o motiva no desenvolvimento de diversas competências, desde reflexões sobre a realidade, revisão bibliográfica, elaboração de instrumentos de investigação, realização de pesquisa de campo e análises dos resultados para produção de novos conhecimentos, que são socializados entre todos os participantes. 
Além disso, o aluno aprende a lidar com incertezas, administrar conflitos, conviver com diferentes visões e trabalhar em equipe, respeitando princípios democráticos. Essas modalidades de aprendizado, além da transparência na atribuição de conceitos ou notas, das quais os alunos participam, autoavaliando-se e avaliando os colegas, contextualizam-se no campo dos valores éticos e da cidadania. A participação dos monitores (alunos dos programas de pós-graduação stricto sensu), além de bem sucedida, é mais uma das contribuições importantes da disciplina de Resolução de Problemas. Com a atuação deles, mantém-se a qualidade da dinâmica pedagógica, e a experiência é importante para o desenvolvimento de suas habilidades docentes.

\section{CONSIDERAÇÕES FINAIS}

Com os avanços das tecnologias da informação e da comunicação, as mudanças no turismo e no lazer foram significativas, e as organizações do mercado exigem cursos cujas propostas pedagógicas sejam pragmáticas. A proliferação dos cursos de ensino à distância contribuiu para a transformação desse cenário. Em contexto de sensível redução de demanda pelos cursos de turismo, vive-se situação controversa, pois ao mesmo tempo em que se fala em formar "mentes pensantes", tem-se a exigência de propostas de formação intensiva e objetiva.

Qual o ponto de equilíbrio dessa situação? A redução de demanda reitera a importância das modalidades de cursos tecnológicos. Várias universidades reformularam o currículo, e a grade curricular é compartilhada com outros cursos, visando a torná-la interdisciplinar. Diversos cursos foram adaptados às linhas da administração, em razão da redução da demanda pela oferta de vagas acadêmicas. Como em qualquer área, o mercado absorve profissionais competentes, mas é preciso repensar os projetos pedagógicos, em razão das mudanças e das expectativas das organizações da sociedade e do mercado.

Qual a postura do professor em sala de aula e do pesquisador acadêmico no atual cenário de incertezas e de questionamentos? Uma das gratificações é que o professor e o pesquisador competentes são exatamente aqueles que questionam e não somente aqueles 
que apresentam respostas ou soluções. Mas, pontualmente, a questão é: como deve ser a atuação docente em turismo e em lazer?

A resposta a essas questões seria a própria reflexão deste artigo sobre a proposta pedagógica da disciplina de Resolução de Problemas II (RP II), ministrada no segundo semestre do Curso de Lazer e Turismo, da Escola de Artes, Ciências e Humanidades (EACH), da Universidade de São Paulo (USP).

Como exemplos, o artigo destacou dez estudos produzidos por grupo de alunos da disciplina de RP II, que abordaram: acessibilidade a parques paulistanos por cadeirantes; serviços da rede hoteleira ao público LGBT; mudanças do lazer infantil; qualidade dos parques públicos paulistanos; atrativos turísticos e culturais e legados Copa do Mundo de 2014; consumo e perfil dos frequentadores de festival musical na cidade de São Paulo; aspectos inovadores de restaurantes e gastronomia de experiência; práticas noturnas de lazer e convivência na região paulistana da Baixa Rua Augusta; e atuação de agências de viagens no segmento de pessoas com deficiências de mobilidade.

Em síntese, os trabalhos produzidos pelos grupos de alunos são resultados do intercâmbio de ideias, por meio de discussões em sala de aula e de pesquisas de campo. Instiga-se os alunos a observar a realidade e a buscar atualização teórica com base em publicações na área, ainda que a leitura seja cada vez mais utópica na realidade da comunicação eletrônica virtual, em que a internet torna-se hegemônica.

A visão de que o aprendizado pode ser conquistado de várias formas, e o professor não é único detentor de conhecimentos é ainda mais evidenciada. Os métodos tradicionais de ensino são questionados, e o educador encontra-se na condição de saber administrar novos instrumentos e dinâmicas pedagógicas criativas, articulando conteúdos e estimulando o aluno a participar como protagonista da própria formação.

Ao mesmo tempo, o professor é, contraditoriamente, desafiado a mostrar domínio de conteúdos e, principalmente, competência de análise sistêmica e crítica da realidade, aplicando a teoria, por meio de ciclos produtivos de interação entre os conceitos e a prática profissional. Esse cenário é inerente a todas as áreas de conhecimento, e, talvez, o ensino em turismo e lazer seja ainda mais desafiador e angustiante, em meio ao quadro de problemas do país. 
É fundamental que esses ensinamentos e os conhecimentos produzidos academicamente sejam aplicados pelos próprios pesquisadores, nos ambientes internos dos departamentos das universidades, em espírito de equipe, interdisciplinar e transdisciplinar. Maior interação, intercâmbio e cooperação entre os docentes e pesquisadores e maior envolvimento dos alunos com as organizações da sociedade e do mercado são essenciais para a dinamização e o enriquecimento das propostas pedagógicas e dos métodos e conteúdos didáticos. Ainda é preciso superar o isolacionismo e a solidão da atuação muitos profissionais no ambiente burocrático da academia.

\section{REFERÊNCIAS}

BAPTISTA, I. Dar rosto ao futuro: a educação como compromisso ético. Porto (Portugal): Profedições, 2008.

BENI, M. C. O profissional do turismo na sociedade pós-industrial. In: GASTAL, S.; BENI, M. C.; CASTROGIOVANNI, A. C. Turismo: investigação e crítica. São Paulo: Contexto, 2002.

BONFIM, M. V. S. Por uma pedagogia diferenciada: uma reflexão acerca do turismo pedagógico como prática educativa. Revista Turismo Visão e Ação, v. 12, n. 1, p. 114119, 2010.

BRIDI, G. Formação e atuação do turismólogo no cenário das agências de turismo: contrapondo competências. Dissertação de Caxias. Programa de Pós-graduação em Turismo da Universidade de Caxias do Sul. Caxias do Sul, 2010.

DENCKER, A. Pesquisa em turismo: planejamento, métodos e técnicas. São Paulo: Futura, 2007.

DEWEY, J. Como pensamos: como se relaciona o pensamento reflexivo com o processo educativo, uma exposição. São Paulo: Editora Nacional, 1979a.

Democracia e educação. São Paulo: Editora Nacional, 1979b.

El hombre y sus problemas. Buenos Aires: Editorial Paidós, 1961.

FERREIRA, L. R. Escola do turismo: o papel do educador. Revista Turismo, Visão e Ação, v. 6, n. 2, p. 187-198, 2004.

FREIRE, P. Pedagogia da autonomia. Rio de Janeiro: Paz e Terra, 1996. 
JAFARI, J. El turismo como disciplina científica. Política y Sociedad, v. 42, n. 1, p. 39-56, 2005.

LARA, L. F. O ensino da administração nos cursos de turismo no Brasil e a formação do turismólogo. Turismo: Visão e Ação. v. 12, n. 3, p. 277-298, 2010.

MOESCH, M. A produção do saber turístico. São Paulo: Contexto, 2002.

MOLINA, S. O pós-turismo. São Paulo: Aleph, 2004.

MORIN, E. Os sete saberes necessários à educação do futuro. São Paulo: Cortez; Brasília, DF: UNESCO, 2002.

OLIVA, G. A maioria quer ser inovadora. Revista Veja. Edição n. 2314. São Paulo: Editora Abril, 27 de março de 2013.

PANOSSO NETTO, A. TRIGO, L. G. Cenários do turismo brasileiro. São Paulo: Aleph, 2009.

PANOSSO NETTO, A. Filosofia do turismo: teoria e epistemologia. São Paulo: Aleph, 2011.

SAMPAIO, C. A.; PAIXÃO, D. L. Associativismo e cooperativismo como arranjos socioprodutivos de base comunitária - incubadora social. In: BENI, M. C. Turismo, planejamento estratégico e capacidade de gestão: desenvolvimento regional, rede de produção e cluster. São Paulo: Manole, 2012.

SANTOS, M. C. Prática docente na formação do turismólogo. Revista Brasileira de Pesquisa em Turismo, v. 1, n. 1, 2007.

SANTOS, M. C. dos; OLIVEIRA, A. C. R. M. de; MARINHO, M. F. Pedagogia da hospitalidade: da formação à atuação profissionais em turismo. In: SEMINÁRIO INTERNACIONAL DE TURISMO, 11, 2009, Curitiba: Universidade Federal do Paraná (UFPR) e Universidade Positivo. Anais..., 2009. 1 cd-rom.

SASTRE, G.; MORENO, M. Aprendizagem emocional e resolução de conflitos. São Paulo: Moderna, 2002.

SILVEIRA C. E.; MEDAGLIA, J.; GÂNDARA, J. M. Ensino superior em turismo em busca de novos paradigmas educacionais: problemas, desafios e forças de pressão. Revista Turismo Visão e Ação - Eletrônica, v. 14, n. 1, p. 6 -18, 2012.

SOGAYAR, R. L.; REJOWSKI, M. Ensino superior em turismo em busca de novos paradigmas educacionais: problemas, desafio e forças de pressão. Revista Turismo Visão e Ação - Eletrônica, v. 13, n. 3, p. 282-298, 2011.

STERGIOU, D.; AIREY, D.; RILEY, M. Making sense of tourism. Annals of Tourism Research. v. 35, n. 3, p. 631-649, 2008. 
THOMSOM, J. C. PBL: uma proposta pedagógica. Olho Mágico, 2 (4/5): 7, 1996.

TRENTIN, F.; SILVA, E. M. C. Motivos para a escolha do curso de turismo. Revista Turismo Visão e Ação, v. 12, n. 2, p. 204-215, 2010.

Recebido em: 08-05-2015.

Aprovado em: 08-06-2015. 